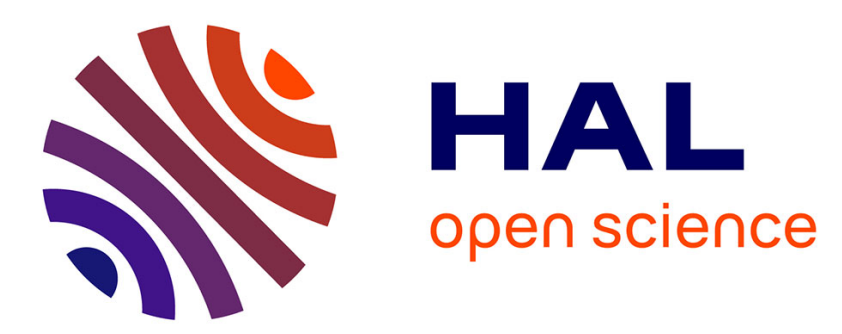

\title{
Use of 3-D Digital Image Correlation to characterize the mechanical behavior of a Fiber Reinforced Refractory Castable
} Laurent Robert, Fabien Nazaret, Thierry Cutard, Jean-José Orteu

\section{- To cite this version:}

Laurent Robert, Fabien Nazaret, Thierry Cutard, Jean-José Orteu. Use of 3-D Digital Image Correlation to characterize the mechanical behavior of a Fiber Reinforced Refractory Castable. Experimental Mechanics, 2007, 47, pp.761-773. 10.1007/s11340-007-9062-8 . hal-00840004

\author{
HAL Id: hal-00840004 \\ https://hal.science/hal-00840004
}

Submitted on 2 Jul 2013

HAL is a multi-disciplinary open access archive for the deposit and dissemination of scientific research documents, whether they are published or not. The documents may come from teaching and research institutions in France or abroad, or from public or private research centers.
L'archive ouverte pluridisciplinaire HAL, est destinée au dépôt et à la diffusion de documents scientifiques de niveau recherche, publiés ou non, émanant des établissements d'enseignement et de recherche français ou étrangers, des laboratoires publics ou privés. 


\title{
Use of 3-D Digital Image Correlation to characterize the mechanical behavior of a Fiber Reinforced Refractory Castable
}

\author{
by \\ Laurent Robert ${ }^{1}$, Fabien Nazaret, Thierry Cutard and Jean-José Orteu \\ Research Center on Tools, Materials and Forming Processes (CROMeP) \\ École des Mines d'Albi \\ Campus Jarlard, 81013 ALBI CT Cedex 9, France
}

Submitted to Experimental Mechanics, August 2006. Revised, June 2007

\footnotetext{
${ }^{1}$ Corresponding author. Fax: +3356349 32 42. E-mail: laurent.robert@enstimac.fr
} 


\section{abstract:}

Refractory castables exhibit very low fracture strain levels when subjected to tension or bending.

The main objective of this work is to show that 3-D digital image correlation (3-D DIC) allows such low strain levels to be measured. Compared to mechanical extensometer measurements, 3-D DIC makes it possible to reach similar strain resolution levels and to avoid the problem of position dependance related to the heterogeneous nature of the strain and to strain localization phenomena.

First, the 3-D DIC method and the experimental set-up are presented. Secondly, an analysis of the 3-D DIC method is performed in order to evaluate the resolution, the standard uncertainty and the spatial resolution for both displacement and strain measurements. An optimized compromise between strain spatial resolution and standard uncertainty is reached for the configuration of the experimental bending test. Finally, the macroscopic mechanical behavior of a fiber reinforced refractory castable (FRRC) is studied using mechanical extensometry and 3-D DIC in the case of tensile and four-point bending tests. It is shown that similar results are obtained with both methods. Furthermore, in the case of bending tests on damaged castable, 3-D DIC results demonstrate the ability to determine Young's modulus from heterogeneous strain fields better than by using classical beam deflection measurements.

keywords: 3-D digital image correlation - refractory castable - fiber - full-field techniques - uncertainty assessment - resolution - spatial resolution 


\section{Introduction}

Full-field optical techniques for displacement or strain measurements are now widely used in experimental mechanics. The main techniques are photoelasticity, geometric moiré, moiré interferometry, holographic interferometry, speckle interferometry (ESPI), grid method and digital image correlation (DIC) [1-4]. It should be noted that some of these techniques can only measure in-plane displacements/strains on planar specimens and some of them can give both in-plane and out-of-plane displacement/strain fields on any kind of specimen (planar or not). Due to its simplicity and versatility, the DIC method is probably one of the most commonly used methods, and many applications can be found in the literature: heterogeneous deformation of foams [5], crack growth of functionally graded materials [6], large deformation of polymers $[7,8]$ for instance. This method can be used with a single camera (standard DIC) to measure in-plane displacement/strain fields on planar objects, or with two cameras (3-D Digital Image Correlation) to measure 3-D displacement/strain fields on any 3-D object [9-11].

DIC method has already been used on concrete samples to measure strains during compression tests [12], to evaluate the damage $[13,14]$ or to characterize localization and cracking phenomena [15]. In most of these studies, the DIC technique was used to characterize the fracture process in concretes. In these cases, DIC is easy to handle because measured displacements are quite large. Recently, Puyo-Pain et al. [16] evaluated the elastic properties of a ceramic brazing joint using DIC-based full-field measurements under tensile, compression and bending loads. They succeeded in measuring very small strains $\left(<10^{-4}\right)$. Orteu et al. [17] have applied the 3-D DIC technique to characterize the behavior of fiber reinforced refractory castables (FRRC) by performing 3-D reconstruction of metallic fibres and 3-D displacement measurement during a tensile test using virtual extensometers.

Refractory castables exhibit very low fracture strain levels in the case of tensile tests [18-21]. Moreover, such granular materials are highly heterogeneous. Consequently, it is difficult to obtain reliable strain values using mechanical extensometers.

The aim of this paper is to show that the 3-D DIC technique has three main advantages for strain measurements of fiber reinforced refractory castables with regard to their elastic behavior: (a) a strain resolution for macroscopic measurements close to that provided by mechanical extensometers, without the problem of the spatial dependance in the position of the extensometer rods, (b) full-field intrinsic potentiality, which gives a description of the 
spatial distribution of strain, and (c) a three-dimensional measurement of the sample shape and the displacement fields, which makes it possible to provide the true surface (2-D) strain tensor fields on 3-D objects.

\section{3-D Digital Image Correlation (3-D DIC)}

\subsection{Principle}

The 3-D DIC method is based on both digital image correlation (DIC) [22] and stereovision, and was developed at the end of the last century $[9,23-26]$. The technique uses a DIC algorithm to determine point correspondences between two images of a specimen acquired from two rigidly bounded cameras. The correlation scores are computed by measuring the similarity of a fixed subset window in the first image to a shifting subset window in the second one. A firstorder two-dimensional shape function in the subset [27] and a zero normalized sum of square difference (ZNSSD) correlation criterion are used. Sub-pixel correlation is performed using quintic B-spline grey level interpolation [28]. After determining the calibration parameters for each camera as well as the 3-D relative position/orientation of the two cameras (pinhole model and radial distortion of 3rd order), the 3-D specimen shape can be reconstructed from the point correspondences using triangulation. To determine the 3-D displacement field, DIC is also used to determine point correspondences between the stereo pairs acquired before and after deformation. The strain field is obtained from the displacement field by numerical differentiation. A complete description of the 3-D DIC technique can be found in the literature, e.g. Luo et al. [24] or Garcia [29]. In this work, we have used the Vic-3D ${ }^{\circledR}$ commercial software [30].

It should be noted that 3-D DIC was used in this work instead of standard 2-D DIC for two main reasons: (a) in 2-D DIC, the specimen must be positioned parallel to the camera sensor and must undergo a planar deformation without any out-of-plane displacement. In practice, this is difficult to guarantee, and an apparent strain could be added to the real strain undergone by the specimen, and (b) due to the calibration requirements of the stereo rig, lens distortions are also corrected for better accuracy measurements. 


\subsection{Experimental set-up}

The stereo rig is composed of two 8-bit Qimaging ${ }^{\circledR}$ Qicam digital cameras with a CCD resolution of $1360 \times 1036$ pixels. Computar $25 \mathrm{~mm}$ f1.3 and Nikkor Nikon $60 \mathrm{~mm}$ f2.8 macro lenses are used in the experiments. Typical magnification factors $g$ are $g_{b}=10.3$ pixels $/ \mathrm{mm}$ for bending tests (Computar lenses) and $g_{t}=28$ pixels $/ \mathrm{mm}$ for tensile tests (Nikkor lenses). Dimensions of the 4-point bending test specimens are $25 \times 25 \times 150 \mathrm{~mm}^{3}$ with a region of interest $(\mathrm{ROI})$ of $25 \times 125 \mathrm{~mm}^{2}$ (in dashed lines in Figure 1 - left). Dimensions of the tensile test specimens are $25 \times 30 \times 30 \mathrm{~mm}^{3}$ in the reduced section with a ROI of $25 \times 46 \mathrm{~mm}^{2}$ (in dashed lines in Figure 1 - right).

[Figure 1 about here.]

Several parameters are involved in the 3-D DIC method: the subset size or correlation window size (cws), the grid step size $p$ of the matched points, and the number of neighboring matched points (nmp) used for the strain computation by discrete derivation. The subset size cws defines the displacement spatial resolution as cws/g (in $\mathrm{mm}$ ). The step size $p$ is chosen as a compromise for obtaining a reasonable smooth displacement field without using an excessive amount of computer time. Typical step sizes are 5 pixels for the bending test images and 10 pixels for the tensile test images. The number of matched points and the step give the $N \times N$ pixels size of the square optical gauge surface, as $N=n m p \times p-1$ (in pixels) or $N / g$ (in mm), which defines the strain spatial resolution.

\section{Optimization of 3-D DIC parameters and metrologi- cal aspects}

In the following, a procedure to estimate practically the resolution and the uncertainty assessment of the 3-D DIC measurements is presented. The analysis is focussed on bending test specimens. The displacement/strain standard uncertainty [31] will be evaluated from the displacement/strain standard deviation, defined by eqn. (1), as:

$$
\sigma(R)=\sqrt{\frac{1}{N b} \sum_{i=1}^{N b}\left(R_{i}^{\text {meas. }}-\mu(R)\right)^{2}}
$$


for which $R$ can be the horizontal displacement $U$ or the strain along the same direction, called $\varepsilon$, measured by DIC or 3-D DIC. $N b$ is the number of the correlated points in the ROI and $\mu(R)$ is the bias (mean value), defined by eqn. (2), as:

$$
\mu(R)=\frac{1}{N b} \sum_{i=1}^{N b}\left(R_{i}^{\text {meas. }}\right)
$$

A speckle analysis is first performed that highlights the quality of the painted speckle pattern. Displacement (section 3.2) and strain (section 3.3) resolution and standard uncertainty are then experimentally estimated.

\subsection{Speckle-pattern analysis}

The analysis was performed on one of the concrete bending test specimen images. A black speckle pattern was randomly sprayed on its flat white painted surface. Several attempts were made to obtain an evenly distributed pattern of black paint drops (Figure 2).

[Figure 2 about here.]

One can observe in Figure 2 that the grey level distribution is not uniform, with lower pixel counts in the 50 to 80 grey level range. Only about 150 grey levels (between 15 and 165) are present.

The size of the speckle ("grain size") is also examined by computing the autocorrelation radius, based on the autocorrelation function of a speckle image [32]. In this work, the autocorrelation radius $D / 2$ is calculated at the height $h$ corresponding to the slope change of the 3-D normalized autocorrelation function peak of the image (see Figure 3). A mean radius of 6.19 pixels with a standard deviation of 2.28 pixels is obtained.

[Figure 3 about here.]

Some studies have been done on our laboratory on synthetic speckle-pattern images with different speckle sizes (mean autocorrelation radii between 2 and 56 pixels), provided by a synthetic speckle texture image generator software $[29,33]$. DIC was performed using Vic$2 \mathrm{D}^{\circledR} \quad$ software between reference and deformed images (imposed rigid displacement of 0.5 pixels, that minimizes the systematic error $[12,34])$ when varying the subset size from 9 to 61 pixels $(9,11,15,21,25,31,41$ and 61$)$. The step size $p$ was chosen as equal to cws so that there is no overlap between neighboring subsets, ensuring the statistical independence of the 
errors. This computation was also done for a step size lower than cws (e.g. $p=5$ pixels) and the same result was observed, showing that for displacement standard deviation assessment, the step size has no influence. It was found that the optimum mean speckle size corresponds to a mean autocorrelation radius of 5.7 pixels - say between 4.8 and 8.7, as presented in Figure 4.

[Figure 4 about here.]

For lower radii, the standard deviation increases as the radius decreases and a slope of - 1 in the log-log graph is regularly observed. In this case, the speckle size is too small compared with the subset size, which means that the speckle is not coded on a sufficient number of pixels (bad over-sampling). For autocorrelation radii greater than 5.7, the standard deviation increases as the radius increases, and very high values are obtained for small subset sizes and large radii. Typically, the size of a large speckle is larger than the subset, giving bad correlation scores. It is worth noting, firstly, that the subset size should be larger than the speckle size, the practical rule of thumb being a subset 3 times larger than the mean speckle size. Secondly, it was noted that increasing the subset size reduces the displacement standard uncertainty but also reduces the displacement spatial resolution.

In conclusion, the autocorrelation radius of the speckle concrete specimen is close to 6 pixels, so we can consider that we have achieved an optimum painted speckle size. However its standard deviation is twice that obtained with a synthetic speckle and its grains are not really randomly distributed.

\subsection{Displacement resolution and uncertainty}

This section deals with an estimation of the displacement resolution and uncertainty based on imposed rigid body displacements of the specimen. Some studies have suggested estimating the displacement errors by imposing rigid displacements to a speckle-pattern specimen [35], generally to evaluate DIC algorithms. In the case of 2-D DIC, the procedure is problematic. Firstly, it is in practice impossible to impose on the specimen a displacement that is perfectly parallel to the CCD sensor plane. Secondly, in the case of a pure translation parallel to the CCD sensor plane, there is no deformation of the subset image, which leads to an optimal (biased) situation for DIC. In the case of 3-D DIC, pinhole projections of the specimen on the two CCD sensors allow a complete and true evaluation to be made of the correlation-based 
image matching and 3-D reconstruction algorithms. This is due to the fact that the specimen plane movements are never parallel to both CCD sensor planes and that there is an apparent projective deformation of the speckle-pattern on the stereoscopic images [29]. This confirms that it is relevant to use solid rigid displacements of a speckle-pattern specimen to evaluate 3-D DIC.

The ultimate displacement resolution related to the image noise can be examined by studying a completely static configuration. The image noise is estimated by recording 5 pairs of images of the painted speckle concrete specimen in standard laboratory conditions without any movement. First, new images are built by image subtraction (pixel-by-pixel) between the first left image (reference image) and the 4 other left images. Then the image noise is estimated by evaluating the grey level distribution of each new image. A mean value of 0.147 grey levels and a standard deviation of 2.108 grey levels are obtained. 3-D DIC is then performed using Vic-3D ${ }^{\circledR}$ between the reference pair of images and the 4 other pairs of images when varying the subset size cws $(11,17,25,35,51$ and 65 pixels). Results are presented in Figure 5 in terms of mean displacement $\mu(U)$ and standard deviation $\sigma(U)$.

[Figure 5 about here.]

For subset sizes greater or equal to 25 pixels, $\sigma(U)$ is equal or less than $0.5 \mu \mathrm{m}\left(5 \times 10^{-3}\right.$ pixels). The bias (mean displacement) is between -1.2 and $0.3 \mu \mathrm{m}\left(-13 \times 10^{-3}\right.$ and $3.2 \times 10^{-3}$ pixels). The displacement resolution can thus be estimated as equal to the noise measurement and is about $0.5 \mu \mathrm{m}\left(5 \times 10^{-3}\right.$ pixels $)$.

Displacement uncertainty by imposing zero-strain 3-D rigid unknown displacements is now presented. A series of 50 pairs of images is recorded on the castable specimen undergoing rigid body motions (typically between 0 and $1 \mathrm{~mm}$ ). 3-D DIC is performed for different values of the subset size, and $\sigma(U)$ is estimated (Figure 6).

[Figure 6 about here.]

For small subsets, $\sigma(U)$ is important. For subset sizes greater than 25 pixels, $\sigma(U)$ decreases and becomes quite constant, and is in the 0.5 to $3 \mu \mathrm{m}$ range. The average value of $\sigma(U)$ for all experiments converges to $1.5 \mu \mathrm{m}$ for subsets greater than 25 pixels. The standard 
deviation of $\sigma(U)$ for all experiments is independent of the subset size and equal to $0.5 \mu \mathrm{m}$. As the displacement standard uncertainty is evaluated from $\sigma(U)$, a good estimation of the displacement standard uncertainty is $1.5 \mu \mathrm{m}$. Note that the random error previously observed without any motion (only image noise) and representative of the displacement resolution was close to $0.5 \mu \mathrm{m}$, while the same tendencies are observed. For the actual image resolution $g_{b}$ $=10.3$ pixels $/ \mathrm{mm}$, the displacement standard uncertainty corresponds to about $1.5 \times 10^{-2}$ pixels.

There is always a compromise between spatial resolution and displacement standard uncertainty: increasing the spatial resolution (lower subset size) increases the displacement uncertainty. We have previously shown that a speckle size corresponding to an autocorrelation radius close to 6 pixels is an optimum size. For a painted speckle size with a mean radius close to 6 pixels, we decided that a good compromise is obtained for a subset size of 25 pixels (i.e. $2.4 \mathrm{~mm}$ ) leading to a displacement standard uncertainty of about $1.5 \mu \mathrm{m}$. In the following, the subset size will be imposed at 25 pixels for the bending test specimens.

Finally, a direct comparison was made between displacements imposed by a micrometer translation stage and measured by the 3-D DIC method. It should be pointed out that our goal is not to qualify the 3-D DIC measurement system, because the resolution and the standard uncertainty of the "reference" measurement method are not well known and are probably of the order of magnitude of the 3-D DIC method, but this comparison acts as an illustration.

A plane metal specimen with a synthetic speckle-pattern, printed on a paper sheet and stuck to it, is fixed on a $1 \mu \mathrm{m}$ resolution translation device. Displacements are imposed by the micrometer in the $1 \mu \mathrm{m}$ to $10 \mathrm{~mm}$ range. A series of images of the speckle-pattern specimen is acquired by a calibrated stereo rig following the previously described conditions. 3-D DIC is then performed on these image pairs. As the axis of the imposed micrometer displacement $\vec{U}_{i m p}$ is unknown, 3-D DIC displacement results are calculated at each correlated point $i$ as the norm of the 3-D measured displacement vector $\vec{U}_{m e s}^{i}$. Results are shown in Figure 7.

[Figure 7 about here.]

The relative error $e$ is given by eqn. (3)

$$
e=\frac{\left|\sum_{i}\left(\left\|\vec{U}_{m e s}^{i}\right\|-\left\|\vec{U}_{i m p}\right\|\right)\right|}{\left\|\vec{U}_{i m p}\right\|} .
$$


An acceptable relative error is observed for displacements greater than $4 \mu \mathrm{m}$. For displacements lower than $2 \mathrm{~mm}$, absolute measured errors are always lower than $10 \mu \mathrm{m}$.

\subsection{Strain resolution and uncertainty}

Strain values resulting from the image noise are first discussed. Strain fields are computed with the post-processor of the Vic-3D ${ }^{\circledR} \quad$ software when varying the number of neighboring matched points nmp used for the strain computation by discrete derivation, i.e. the optical gauge length, for the reference pair of images and the 4 other pairs of images already used in section 3.2. As expected (see Figure 8), $\sigma(\varepsilon)$ decreases as the gauge length increases.

[Figure 8 about here.]

It is worth pointing out that for an optical gauge length equal to the size of the ROI, one finds a unique homogeneous strain value with a zero standard deviation. The bias $\mu(\varepsilon)$ is between $-8 \times 10^{-6}$ and $6 \times 10^{-6}$. The order of magnitude of the strain resolution can thus be estimated as equal to the noise measurement, about $10^{-5}$. For an arbitrary choice of nmp $=15$ and $p=5$, giving a gauge length $(\mathrm{nmp} \times p-1) / g_{b}=7.2 \mathrm{~mm}$, the minimum strain error is close to $3 \times 10^{-5}$.

Strain fields for the 50 rigid body motion experiments discussed in section 3.2 were also computed with Vic-3D ${ }^{\circledR}$ when varying the number of neighboring matched points. One can observe in Figure 9 that in all cases, $\sigma(\varepsilon)$ decreases as the gauge length increases and that the dispersion is quite constant.

[Figure 9 about here.]

For $\mathrm{nmp}=15$ corresponding to a $7.2 \mathrm{~mm}$ strain gauge length, values close to $10^{-4}$ are obtained, with a rather low dispersion (standard deviation of $\sigma(\varepsilon)$ is close to $0.25 \times 10^{-4}$ ). In the present study, this $7.2 \mathrm{~mm}$ strain gauge length is a good compromise between the strain spatial resolution and the strain standard uncertainty $\left(10^{-4}\right)$.

As the true zero strain is known, the bias $\mu(\varepsilon)$ can be calculated, as presented in Figure 10.

[Figure 10 about here.] 
The bias is independent of the strain gauge length: values are in the $-2 \times 10^{-5}$ to $6 \times 10^{-5}$ range, but the mean value for bias is lower than $10^{-5}$ with a standard deviation of $2 \times 10^{-5}$.

As a conclusion, strain standard uncertainty is dependent on the strain gauge length, typically about $10^{-4}$ for a $7.2 \mathrm{~mm}$ strain gauge length, but the mean strain error on the ROI is independent of the strain gauge length and its value is a decade lower: the systematic strain error is lower than $10^{-5}$.

\subsection{Synthesis}

We have shown that the optimal speckle size corresponds to a mean radius close to 6 pixels. For the textured bending test specimen, we have shown that a displacement spatial resolution of cws $/ g_{b}=2.4 \mathrm{~mm}$ obtained with a subset size cws $=25$ pixels is a good compromise and that the displacement standard uncertainty of the 3-D DIC in the configuration of this work could be estimated at $1.5 \mu \mathrm{m}$. Using an optical gauge of 15 neighboring matched points which is a good compromise between the strain spatial resolution of $(15 \times p-1) / g_{b}=7.2 \mathrm{~mm}$ (for a step $p=5$ ) and the strain standard uncertainty estimated to $10^{-4}$, the systematic strain error on the ROI is lower than $10^{-5}$.

For the tensile test specimens, and based on the same analysis, the chosen subset size is $\mathrm{cws}=40$ pixels, thus the displacement spatial resolution is $\mathrm{cws} / g_{t}=1.43 \mathrm{~mm}$ and the strain spatial resolution is $(15 \times p-1) / g_{t}=5.32 \mathrm{~mm}$ (for a step $\left.p=10\right)$.

\section{Mechanical behavior of a fiber reinforced refractory castable studied by $3-\mathrm{D}$ DIC}

\subsection{Material and experimental methods}

\subsubsection{Fiber reinforced refractory castable (FRRC)}

The FRRC in question is a geopolymer based refractory castable reinforced with $1.5 \%$ vol. of metallic fibres. The FRRC formulation and processing route have been detailed in previous papers [36,37]. The maximum aggregate size is of $3 \mathrm{~mm}$ and metallic fibers have a 12.5 mm length and a $0.38 \mathrm{~mm}$ diameter. After a $80^{\circ} \mathrm{C}$ drying step, the $\mathrm{FRRC}$ is fired in order to stabilize the microstructure for high temperature applications. Such heat treatment is 
known to generate damage in the FRRC microstructure. This is mainly due to the differential dilatometric behaviors of the matrix, of the aggregates and of the metallic fibres $[37,38]$. Damage mechanisms deal with aggregate/matrix decohesions, fiber/matrix decohesions and with matrix microcracking. Three firing temperatures are considered: $110^{\circ} \mathrm{C}, 500^{\circ} \mathrm{C}$ and $900^{\circ} \mathrm{C}$. The higher the firing temperature, the higher the damage level [20]. As a consequence, for each firing temperature, the mechanical behavior and the microstructure of the FRRC are different.

\subsubsection{Experimental methods}

Uniaxial tensile tests are performed at room temperature on a MTS 810 servo-hydraulic universal testing machine by means of a non-articulated tensile system (Figure 11 on the left). Sample extremities are glued on metallic plates. The specimen geometry has been defined to concentrate the highest stress levels in a reduced cross-section of $30 \times 25 \mathrm{~mm}^{2}$. Strain measurements can be performed using mechanical extensometers that are characterized by a $12.5 \mathrm{~mm}$ gauge length. A grinding operation is performed on the two opposite faces where the spray painted speckle is applied and the extensometers are placed. A parallelism error lower than $0.05 \mathrm{~mm}$ is obtained between these two faces. A particular attention is paid to obtaining the best possible alignment between the sample axis and the machine loading axis in order to minimize parasitic bending. Monotonic tests and cyclic loading/unloading tests are performed at a crosshead displacement velocity of $0.04 \mathrm{~mm} / \mathrm{min}$.

[Figure 11 about here.]

For 4-point bending tests, a specific device installed on the same universal testing machine is used (Figure 11 on the right). Several works have shown that experimental results of bending tests are very sensitive to the boundary conditions, like the geometry of the loading contacts and the degrees of freedom of the contact supports [39,40]. As a consequence, some precautions have been taken in order to minimize the error sources that have been previously identified when testing ceramics. Loading is applied with alumina parts. The two lower alumina rollers are $125 \mathrm{~mm}$ spaced and supported by a fixed base. The two upper rollers are $45 \mathrm{~mm}$ spaced and are supported by a free rotation universal joint. Samples have a $150 \mathrm{~mm}$ length and a $25 \times 25$ $\mathrm{mm}^{2}$ cross-section. The lower and upper faces of the sample are machined by grinding to obtain a parallelism error lower than $0.05 \mathrm{~mm}$ between these two faces. Measurement of the sample 
deflection is made by a linear variable displacement transducer coupled with a fine alumina rod that is in contact with the central point of the sample lower face. Both monotonic tests and loading/unloading cyclic tests have been performed at a constant crosshead displacement velocity of $0.02 \mathrm{~mm} / \mathrm{min}$.

The theory of elasticity is applied to calculate Young's modulus $E$ and the nominal strength $\sigma$ on the tension sample face:

$$
\begin{gathered}
\sigma=\frac{3 P(L-l)}{2 b h^{2}} \\
E=\frac{P}{d} \frac{1}{8 b h^{3}}(L-l)\left(2 L^{2}+2 L l-l^{2}\right)
\end{gathered}
$$

where $P$ is the applied load; $b$ and $h$ are respectively the width and the height of the specimen; $L$ and $l$ are the distances between the lower and the upper loading rollers and $d$ is the sample deflection.

\subsection{Exploitation of strain fields measured by 3-D DIC during me- chanical tests}

For both tensile and bending tests, the 3-D DIC method is used to determine strain fields and strain mean values. Parameters of the 3-D DIC method retained in this part of the study are those described and justified in section 3. During mechanical tests, one pair of images is stored every $500 \mathrm{~ms}$.

As mentioned in section 3 , the strain standard uncertainty is close to $10^{-4}$. This is quite a high value compared to the strain levels which characterize the FRRC behavior under tension. On the other hand, the mean value for the systematic strain error is close to $10^{-5}$. As a consequence, for each step of strain determination by 3-D DIC, a mean value of the local strain determined at each point of the considered ROI is calculated. This approach is based on the assumption that this macroscopic strain value remains reliable in spite of the large spatial strain random error.

Furthermore, the mean value for the strain bias is lower than $10^{-5}$ but with a standard deviation of $2 \times 10^{-5}$ (see Figure 10). Consequently, to avoid a large scattering of the strain measurements by 3-D DIC after the spatial averaging, it was decided to smooth the 3-D DIC strain versus time curve. Thus, for each point of the curve, a strain mean value was calculated by 3-D DIC from seven image pairs. They deal with the image pair of the considered point and with the image pairs of the three previous and three following points. 
Results of this method are illustrated by considering the case of a cyclic tensile test performed on a sample fired at $500^{\circ} \mathrm{C}$. During this test, the strain was also measured by a mechanical extensometer. The temporal evolutions of strains calculated by 3-D DIC are superposed onto the extensometer measurements before (Figure 12, left) and after applying smoothing (Figure 12, right).

[Figure 12 about here.]

An examination of these two figures reveals the beneficial reduction of the scattering amplitude which is obtained after applying the smoothing procedure. Because of the high image storing rate compared to the crosshead displacement velocity, the smoothing procedure does not greatly affect the temporal evolutions of the 3-D DIC strain. In this study, strain curves calculated by 3-D DIC will ultimately be smoothed using this method. As a preliminary comment, it can be observed that the 3-D DIC strain evolutions are close to the evolutions of the strain measured by the mechanical extensometer. Such comparison must be made carefully. Particularly, it must not be overlooked that the mechanical extensometer measurements are sensitive to the localization of the alumina rod tips compared to the microstructural heterogeneities and to strain localization phenomena.

The general macroscopic behavior of the FRRC in question has already been discussed in previous papers $[20,41]$. Some significant results will now be considered in order to illustrate the benefits of coupling the 3-D DIC method to mechanical tests.

\subsection{Mechanical tests}

\subsubsection{Tensile test results}

Results of tensile tests performed on FRRC have already been presented and discussed [20, 21,41]. Generic comments can be made to describe the room temperature tensile behavior. At the beginning of the first loading, a linear elastic behavior is observed. When the stress level increases, the behavior moves to a non-linear one. This is due to microcracking damage processes that occur in the FRRC. At the stress peak, one or several macrocracks appear in the tensile test sample. The behavior moves to a softening part, because of the presence of fibers that bridge the macrocracks. During the application of loading/unloading cycles, permanent strains and hysteresis loops are measured. This must be related to the energy loss by internal friction in the microcracks. 
When considering the $500^{\circ} \mathrm{C}$ fired FRRC, Figure 13 makes a comparison between the two behavior curves which can be obtained either from the 3-D DIC strain values or from those given by the extensometer.

[Figure 13 about here.]

It can be observed that the behavior curve plotted from the 3-D DIC values follows the behavior curve plotted with the values measured by the extensometer. Permanent strain values are higher during loading/unloading loops in the case of 3-D DIC measurements. A small difference is also obtained for the strain at the peak stress between the two methods. These differences must be related to the strain localization phenomena which occur during the concrete cracking processes. The strains measured by the extensometer are more dependent on crack location sites. Indeed, the 3-D DIC method gives a mean value of the strain field which takes into account all local strain gradients which characterize the surface being considered. As a consequence, all microcracks are integrated wherever they initiate. Thus, the 3-D DIC method allows access to a macroscopic strain field less dependent on crack locations. Moreover, some differences between the two measurements may come from the fact that strains are not measured on the same face of the tensile test sample. Even if particular attention is paid to the sample preparation and alignment procedures, some bending components can appear in the sample during the test because of material heterogeneities and because of the non symmetry of damage processes. Such effects have already been exposed and discussed by Nazaret et al. $[20]$.

Considering the first linear elastic domain, Young's modulus values calculated from the 3-D DIC tensile test curves are presented in Table 1.

[Table 1 about here.]

They are compared to Young's modulus values determined from extensometer measurements performed both in the field of the present work and in previous works without applying the 3-D DIC method [41]. Young's modulus values obtained from extensometer measurements are the results of merging and averaging the data of five tests for each firing temperature. The scattering of Young's modulus values which is obtained is normal for such heterogeneous material. As can be seen, Young's modulus values determined by the 3-D DIC method are very close to those obtained from the extensometer values. 


\subsubsection{Four point bending test results}

In this bending load case, the strain field is highly heterogeneous. As a consequence and because of the behavior specificities of damaged refractory castables, care must be taken when characterizing their tension behavior and determining their Young's modulus from bending tests. As discussed in a previous paper [20], considering the beam deflection can lead to large errors in the determination of Young's modulus. Some results will now be considered to show that performing the 3-D DIC method on FRRC bending samples can be particularly useful in making such a determination. In the present work, the strain field is evaluated by 3-D DIC following the previously detailed method. At each storing time, a macroscopic value of the longitudinal strain is determined by calculating the strain mean value of a $45 \mathrm{~mm}$ width and $1 \mathrm{~mm}$ height strain field. As detailed in Figure 14, this field is obtained by considering an area located between the two upper loading rollers and in the lower part of the vertical face of the bending sample.

[Figure 14 about here.]

Young's modulus is then determined by performing a linear fitting between the applied load values $(P)$ and the 3 -D DIC strain values considering the theory of elasticity (eqn. (6)):

$$
E=\frac{3 P(L-l)}{2 \varepsilon b h^{2}}
$$

where $E$ is Young's modulus and $\varepsilon$ the longitudinal strain measured by the $3-\mathrm{D}$ DIC method. Even if the area under consideration has a small height compared to its width, it takes into account a vertical strain gradient. As a consequence, the calculated strain mean value is a minor value of the true tension strain which specifically characterizes the lower face of the bending sample. Thus, this leads to an overestimation of Young's modulus when it is determined from such 3-D DIC measurements and from eqn. (6). 3-D DIC strains are computed using a square optical gauge of $7.2 \times 7.2 \mathrm{~mm}^{2}$ in size. This corresponds to the strain spatial resolution as described in section 3. Because of this strain spatial resolution and of the strain gradient, calculating the 3-D DIC strain value at the lower limit of the considered area (i.e. at the bottom edge of the sample) means the strain mean value is determined at $7.2 / 4=1.8 \mathrm{~mm}$ from the edge. On the other hand, when the strain is calculated at the upper limit of the considered area, the value obtained corresponds to the longitudinal strain at $(7.2 / 2+1) / 2=2.3 \mathrm{~mm}$ from the bottom edge of the sample. Thus, considering that the strain gradient is linear between 
the lower sample edge and the neutral axis, the overestimation of Young's modulus can be estimated as being in the $14.4 \%$ to $18.4 \%$ range. It must be noticed that this overestimation of strain values is not an intrinsic property of the 3-D DIC method. In this method, the strain resolution is directly related to the image characteristics and may be greatly reduced for example when considering a larger sample or a larger magnification.

For both tensile and 4-point bending tests, values of the FRRC Young's modulus are presented in Table 1 and for the three firing temperatures. The values have been obtained from the 3-D DIC method for tensile tests and bending tests and also from extensometer measurements in the case of tensile tests. For the $500^{\circ} \mathrm{C}$ and $900^{\circ} \mathrm{C}$ firing temperatures, all the values obtained from bending tests are in the uncertainty range of those obtained from tensile tests. It may seem surprising not to find a systematic overestimation of Young's modulus values obtained from the 3-D DIC method because of the previously described strain gradient phenomenon. This must be related to the specific mechanical behavior which characterizes the FRRC for such firing temperatures. As shown and discussed in a previous paper [20], because of the damage which develops during such firing cycles, microcracking processes occur as soon as the mechanical loading of the fired FRRC starts and even if a linear domain characterizes the behavior curves. For 4-point bending tests, microcracks initiate at the bottom edge of the sample, i.e. precisely in the area which is considered for applying the 3-D DIC method. Consequently, 3-D DIC strains are overestimated and Young's modulus values are underestimated. Thus, there are two phenomena which have opposite effects on the determination of Young's modulus. This can explain why the 3-D DIC Young's modulus values obtained from bending tests are close to those obtained from tensile tests. For the $110^{\circ} \mathrm{C}$ drying temperature, Young's modulus is overestimated $(+11.5 \%)$ when considering the 3-D DIC results for the bending test. As previously shown [20], microcrack processes are less active when loading the $110^{\circ} \mathrm{C}$ FRRC. This is due to the low damage state which results from a $110^{\circ} \mathrm{C}$ drying cycle compared to high temperature firing ones. As a consequence, the overestimation of the 3-D DIC Young's modulus values has a major influence.

Another way to compare the 3-D DIC strain evolutions with macroscopic measurements is proposed in Figure 15 by considering the results of a monotonic 4-point bending test performed on a $110^{\circ} \mathrm{C}$ dried sample.

[Figure 15 about here.] 
Macroscopic strains correspond to the strain of the bottom sample face and is calculated on one hand from the load measurements by considering the theory of elasticity and Young's modulus determined during tensile tests, and on the other hand by 3-D DIC measurement applied on the area defined in Figure 14. By comparing the two curves it is possible to conclude that 3-D DIC strain levels are underestimated and that the two strain evolutions remain similar up to the sample fracture.

For damaged concretes, these results demonstrate the ability to determine Young's modulus from the 3-D DIC method even when considering the case of heterogeneously loaded structures like bending beams. Indeed, despite of the uncertainty which characterizes these values, they give better results compared to those obtained from mechanical beam deflection measurements. This is mainly due to the fact that 3-D DIC strain calculations do not consider the influence of the contact areas between the sample and loading rollers. As previously discussed [20], the discrepancies between Young's modulus values measured during tensile tests and 4-point bending tests are due to local strain effects which take place at the roller/sample contacts and influence the deflection measurement during bending tests.

\section{Conclusion}

Refractory castables exhibit very low strain levels before fracture when subjected to tension or bending. At peak stress these levels are of the order of magnitude of $10^{-4}$. In the present work, it has been shown that 3-D DIC makes it possible to measure such small strain levels with a resolution close to $10^{-5}$. As a consequence, this method is useful to quantify the low strain levels that characterize reinforced or unreinforced refractory castables during tensile and bending tests. Furthermore, care must be taken when choosing the 3-D DIC parameter values by taking into account the nature and the scale of the mechanical problem under consideration. In the present paper, choices have been justified by way of a metrological analysis of 3-D DIC, in order to evaluate the resolution, the standard uncertainty and the spatial resolution for both displacement and strain measurements.

The optimal speckle size / subset size pair has been determined from the analysis of synthetic speckle-pattern images. An image noise analysis has been carried out in order to estimate the displacement and the strain resolutions. The displacement and the strain standard uncertainties have been evaluated using a sprayed FRRC bending specimen undergoing 
rigid body motions. An optimized compromise between the strain spatial resolution and strain standard uncertainty has been reached, with a systematic strain error lower than $10^{-5}$.

Tensile and 4-point bending tests were performed using both the 3-D DIC technique and mechanical extensometers. Strain values measured by 3-D DIC are in agreement with strain values measured by mechanical extensometers. Moreover, extensometer values remain highly dependent on their location on the sample because of FRRC heterogeneities and because of strain localization phenomena. As the 3-D DIC method can determine a strain mean value by averaging all the strain values of the field being considered, the material heterogeneity becomes less influential. In this study, only macroscopic strain values have been monitored to characterize the mechanical behavior. Full-field measurements could give complementary information particularly when considering cracking processes.

A method that takes into account the strain gradient and the cracking processes has been exposed in the case of a bending test. It illustrates the potentialities of the 3-D DIC method for a structure subjected to a heterogeneous loading. As an example, it has been shown that the material Young's modulus can be determined from the 3-D DIC method by considering part of the strain field of a bending sample face. As previously discussed, this cannot be obtained by measuring the bending beam deflection because of the non-linear behaviors that characterize damaged refractory castables. From now on, the 3-D DIC method can give some useful and complementary data when studying the mechanical behavior of such materials. These results are highly encouraging when considering that camera resolution will continue to improve in the future. Another interesting step would be to adapt the 3-D DIC method in order to be able to perform high temperature measurements.

\section{Acknowledgment :}

The authors wish to acknowledge Correlated Solutions Inc. for providing the Vic-2D ${ }^{\circledR}$ and Vic-3D ${ }^{\circledR}$ softwares. The authors are grateful to ACB, Airbus France, Hurel-Hispano, Pyromeral Systems and Vesuvius for their technical and financial support. 


\section{References}

[1] Cloud G. (1998) Optical Methods of Engineering Analysis. Cambridge University Press, iSBN 0-521-45087-X.

[2] Rastogi P. (ed.) (1999) Photomechanics. Springer Verlag, iSBN 3-540-65990-0.

[3] Surrel Y. (2004) Full-field optical methods for mechanical engineering: essential concepts to find one's way. invited keynote at the 2nd International Conference on Composites Testing and Model Identification, Bristol, U.K.

[4] Grédiac M. (2004) The use of full-field measurement methods in composite material characterization: interest and limitations. Composites Part A, 35:751-761.

[5] Wang Y. and Cuitiño A. (2002) Full-field measurements of heterogeneous deformation patterns on polymeric foams using digital image correlation. International Journal of Solids and Structures, 39:3777-3796.

[6] Abanto-Bueno J. and Lambros J. (2002) Investigation of crack growth in functionally graded materials using digital image correlation. Engineering Fracture Mechanics, 69:1695-1711.

[7] Chevalier L., Calloch S., Hild F., and Marco Y. (2001) Digital image correlation used to analyze the multiaxial behavior of rubber-like materials. Eur. J. Mech. A - Solids, 20:169-187.

[8] Parsons E., Boyce M., and Parks D. (2004) An experimental investigation of the largestrain tensile behavior of neat and rubber-toughened polycarbonate. Polymer, 45:26652684 .

[9] Helm J., McNeill S., and Sutton M. (1996) Improved three-dimensional image correlation for surface displacement measurement. Opt. Eng., 35(7):1911-1920.

[10] Sutton M., McNeill S., Helm J., and Chao Y. (2000) Advances in Two-Dimensional and Three-Dimensional Computer Vision. Rastogi P. (ed.), Photomechanics, Topics in Applied Physics, Springer Verlag, Berlin. 
[11] Garcia D., Orteu J.-J., and Penazzi L. (2002) A combined temporal tracking and stereocorrelation technique for accurate measurement of 3D displacements: application to sheet metal forming. Journal of Materials Processing Technology, 125-126:736-742.

[12] Choi S. and Shah S. (1997) Measurement of deformations on concrete subjected to compression using image correlation. Experimental Mechanics, 37(3):307-313.

[13] Lawler J., Keane D., and Shah S. (2001) Measuring three-dimensional damage in concrete under compression. ACI Materials Journal, 98:465-475.

[14] Zhang J., Xiong C., Li H., Li M., Wang J., and Fang J. (2004) Damage and fracture evaluation of granular composite materials by digital image correlation method. Acta Mechanica Sinica, 20(4):408-417.

[15] Lecompte D., Vantomme J., and Sol H. (2006) Crack detection in a concrete beam using two different camera techniques. Structural Health Monitoring, 5(1):50-68.

[16] Puyo-Pain M. and Lamon J. (2005) Determination of elastic moduli and Poisson coefficient of thin silicon-based joint using digital image correlation. Proceedings of the 29th International Conference on advanced Ceramics and Composites, Cocoa Beach, Florida, USA.

[17] Orteu J.-J., Cutard T., Garcia D., Cailleux E., and Robert L. (2007) Application of stereovision to the mechanical characterisation of ceramic refractories reinforced with metallic fibres. Strain, 43(2):1-13.

[18] Schmitt N., Berthaud Y., and Poirier J. (2000) Tensile behaviour of magnesia carbon refractories. Journal of the European Ceramic Society, 20:2239-2248.

[19] Marzagui H., Cutard T., Yeugo Fogain E., Huger M., Gault C., Prompt N., and Deteuf C. (2004) Microstructural changes and high temperature mechanical behavior of an andalusite based low cement refractory castable. Proceedings of the International Conference of Metallurgists (COM2004), Hamilton, Canada, pp. 331-345.

[20] Nazaret F., Marzagui H., and Cutard T. (2006) Influence of the mechanical behaviour specificities of damaged refractory castables on the Young's modulus determination. Journal of the European Ceramic Society, 76(8):1429-1438. 
[21] Nazaret F., Cutard T., and Bernhart G. (2004) Thermomechanical behaviour of a fibrereinforced refractory concrete: tests and FE analysis. Proceedings of the 6th RILEM Symposium on Fibre Reinforced Concrete (BEFIB 2004), Varenna, Lake Como, Italy, pp. 689-698.

[22] Sutton M., Wolters W., Peters W., and McNiell S. (1983) Determination of displacements using an improved digital correlation method. Image and Vision Computing, 1:133-139.

[23] Kahn-Jetter Z. and Chu T. (1990) Three-dimensional displacement measurements using digital image correlation and photogrammic analysis. Experimental Mechanics, 30(1):1016.

[24] Luo P., Chao Y., Sutton M., and Peters W. (1993) Accurate measurement of threedimensional deformations in deformable and rigid bodies using computer vision. Experimental Mechanics, 30(2):123-132.

[25] Alpers B., Bergmann D., Galanulis K., and Winter D. (1999) Advanced deformation measurement in sheet metal forming. Proceedings of the 6th International Conference on Technology of Plasticity, Nuremberg, Germany.

[26] Synnergren P. and Sjödahl M. (1999) A stereoscopic digital speckle photography system for 3-D displacement field measurements. Optics and Lasers in Engineering, 31:425-443.

[27] Schreier H. and Sutton M. (2002) Systematic errors in digital image correlation due to undermatched subset shape functions. Experimental Mechanics, 43(3):303-311.

[28] Schreier H., Braasch J., and Sutton M. (2000) Systematic errors in digital image correlation caused by intensity interpolation. Opt. Eng., 39(11):2915-2921.

[29] Garcia D. (2001) Mesure de formes et de champs de déplacements tridimensionnels par stéréo-corrélation d'images. Ph.D. thesis, Institut National Polytechnique de Toulouse (France).

[30] (2006), Vic-2D ${ }^{\circledR}$ and Vic-3D ${ }^{\circledR} \quad$ softwares, Correlated Solutions Incorporated, http://www.correlatedsolutions.com/.

[31] (1995), ISO Guide to the Expression of Uncertainty in Measurements (GUM). International Organization for Standardization, Geneva (Switzerland). 
[32] Rubin D. (2004) A simple autocorrelation algorithm for determining grain size from digital images of sediment. Journal of Sedimentary Research, 74(1):160-165.

[33] Orteu J.-J., Garcia D., Robert L., and Bugarin F. (2006) A speckle-texture image generator. Proceedings of the Speckle'06 International Conference, Nîmes, France.

[34] Wattrisse B., Chrysochoos A., Muracciole J.-M., and Némoz-Gaillard M. (2000) Analysis of strain localization during tensile tests by digital image correlation. Experimental Mechanics, 41(1):29-39.

[35] Jin H. and Bruck H. (2005) Theoretical Development for Pointwise Digital Image Correlation. Optical Engineering, 44(6):1-14.

[36] Davidovits J. (1994) Geopolymers: man-made rock geosynthesis and resulting development of very early high strength cement. Journal of Materials Education, 16:91-139.

[37] Cutard T., Cailleux E., Lours P., and Bernhart G. (1999) Structural and mechanical properties of a refractory concrete for superplastic forming tools. Industrial Ceramics, 19:100-102.

[38] Cailleux E., Cutard T., and Bernhart G. (2005) Pullout of steel fibres from a refractory castable: experiment and modelling. Mechanics of Materials, 37:427-445.

[39] Quinn G. (1990) Flexure strength of advanced structural ceramics: a Round Robin. Journal of the American Ceramic Society, 73:2374-2384.

[40] Quinn G. and Morrell R. (1991) Design data for engineering ceramics: a review of the flexure test. Journal of the American Ceramic Society, 74:2037-2066.

[41] Nazaret F. (2005) Caractérisation et modélisation du comportement thermomécanique d'un béton réfractaire renforcé de fibres métalliques. Ph.D. thesis, École des Mines de Paris (France). 

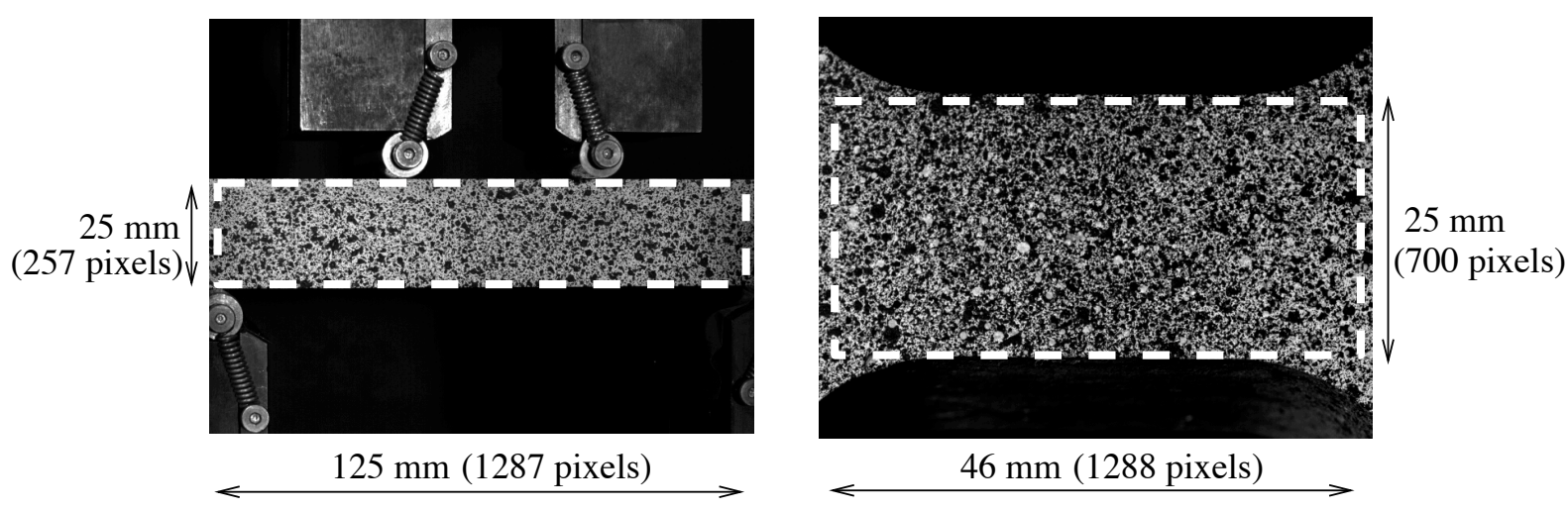

Figure 1: Region of interest (ROI) in dashed line for the bending test specimen (left) and for the tensile test specimen (right). A random speckle pattern is obtained by projection of a spray paint (black speckles on a white background) 

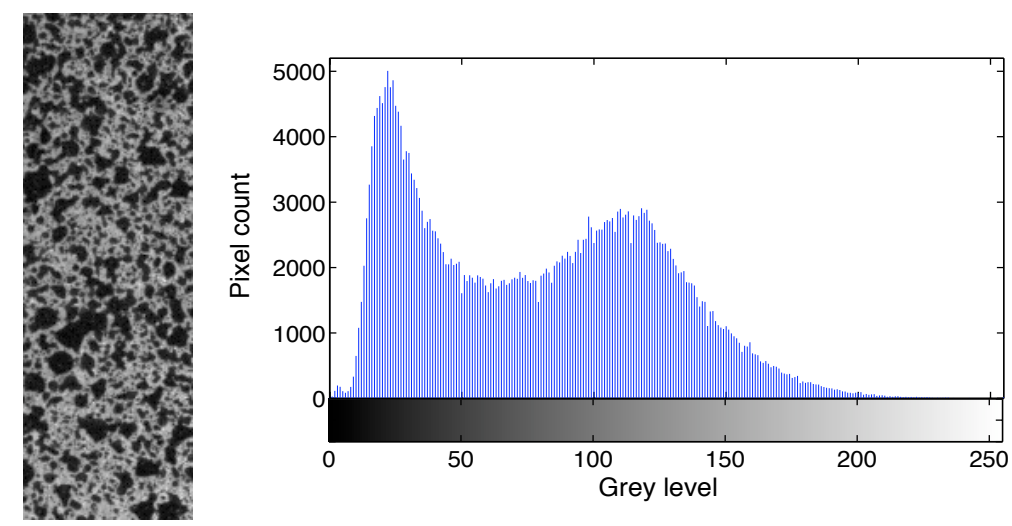

Figure 2: Experimental speckle-pattern image obtained by projection of black paint drops on a white background on the bending test castable specimen, and its associated grey level distribution $(300 \times 100$ pixels sub-image, extracted from the entire ROI of the specimen image of $1360 \times 260$ pixels $)$. 


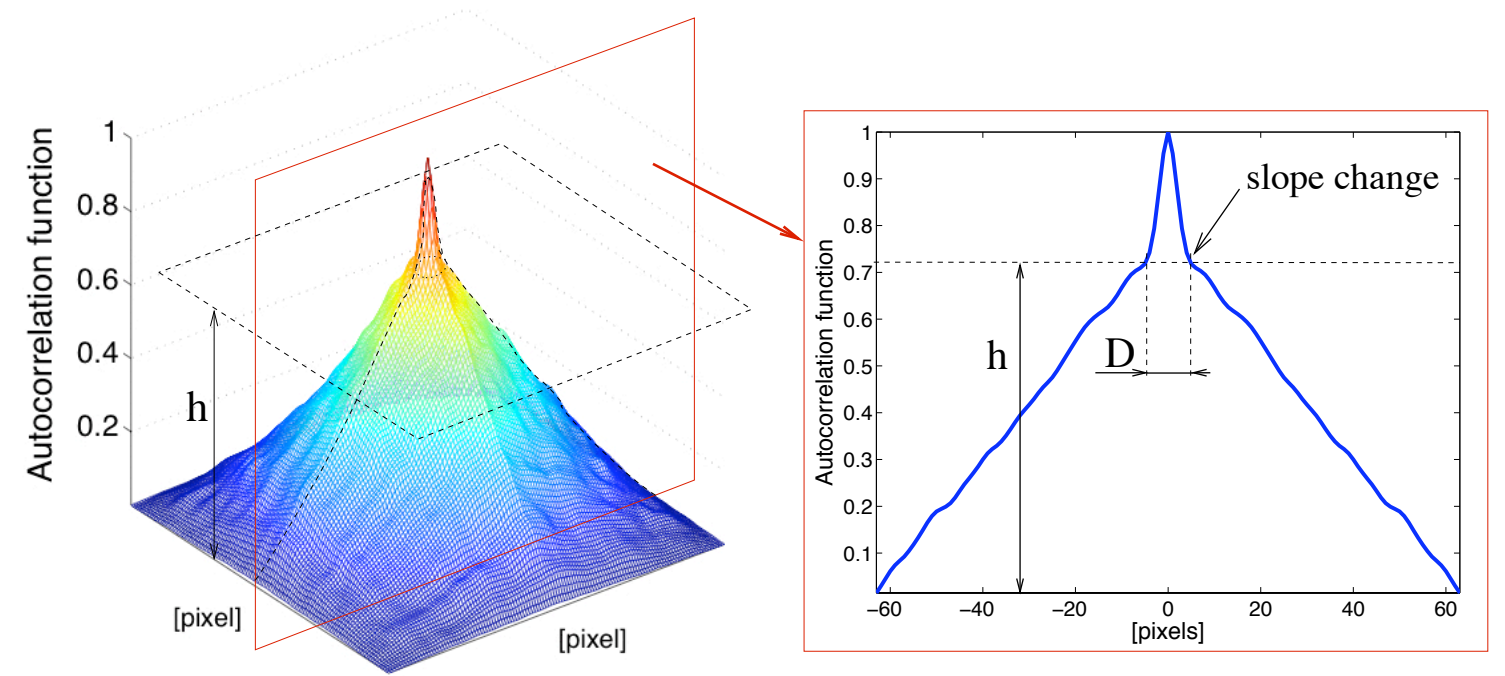

Figure 3: Autocorrelation function: definition of the height $h$ used for computing the autocorrelation radius $D / 2$. 


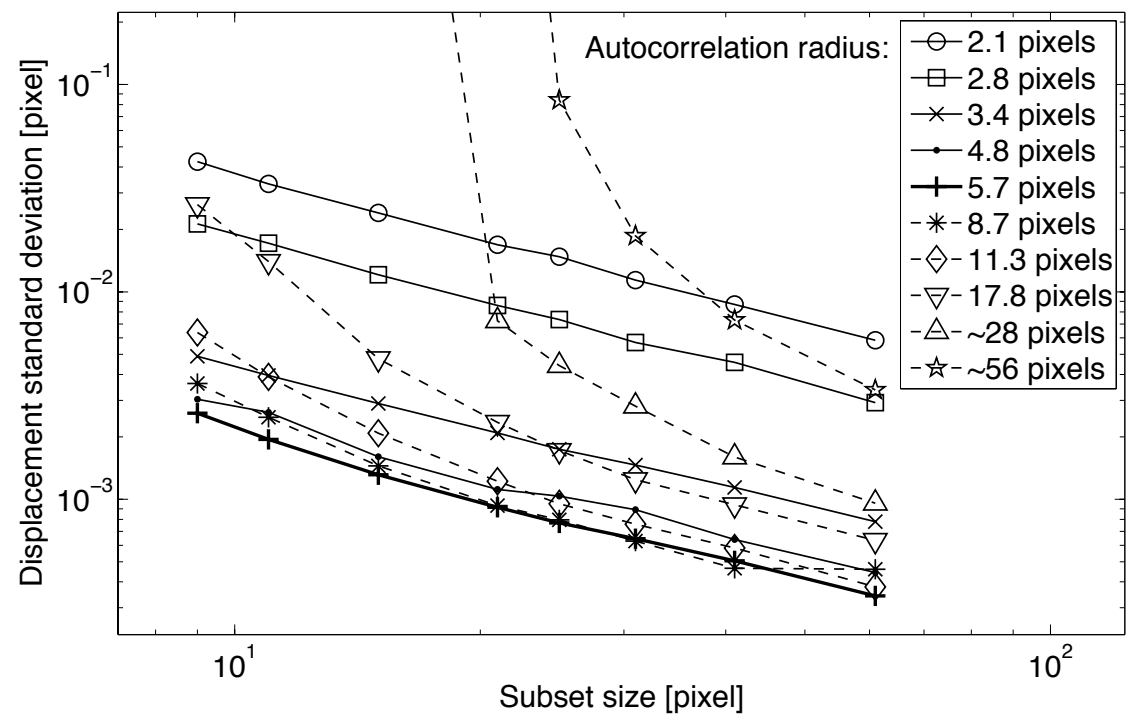

Figure 4: Plot of the displacement standard deviation between measured and prescribed displacements versus the subset size, for ten distinct speckle-pattern sizes. 


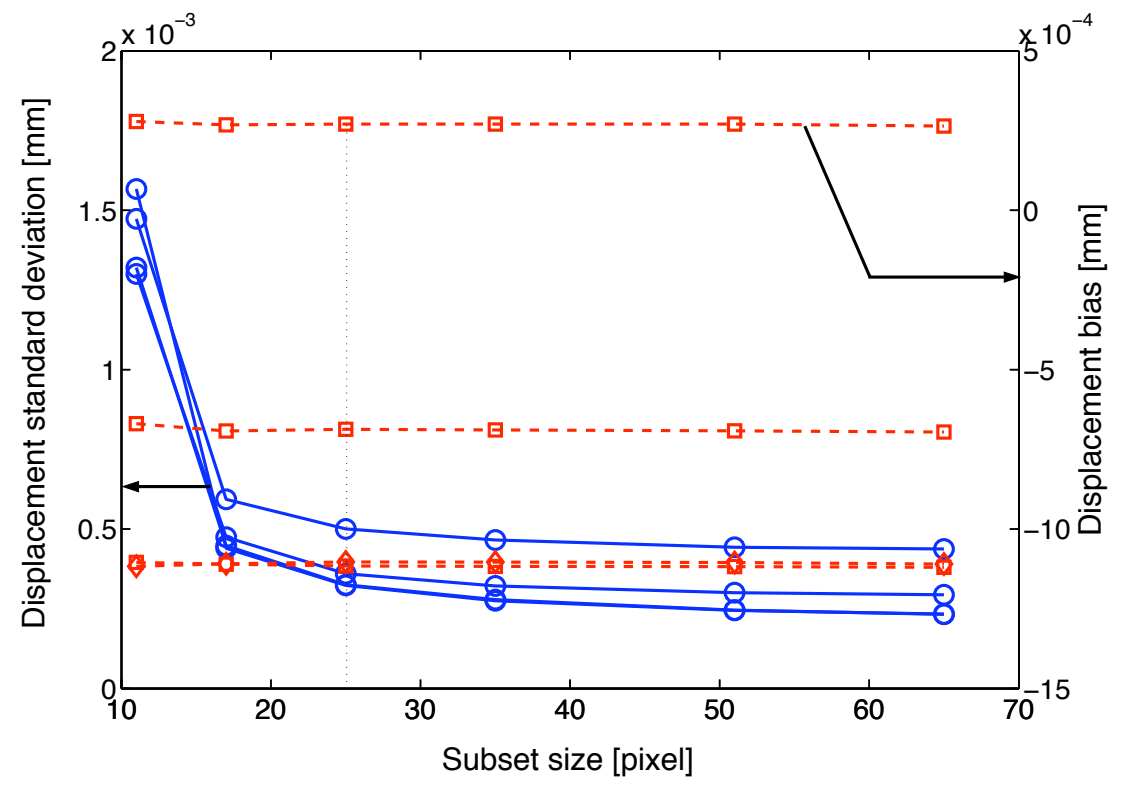

Figure 5: Plots of $\mu(U)$ (square) and $\sigma(U)$ (circle) calculated by 3-D DIC for specimen images without any movement. 


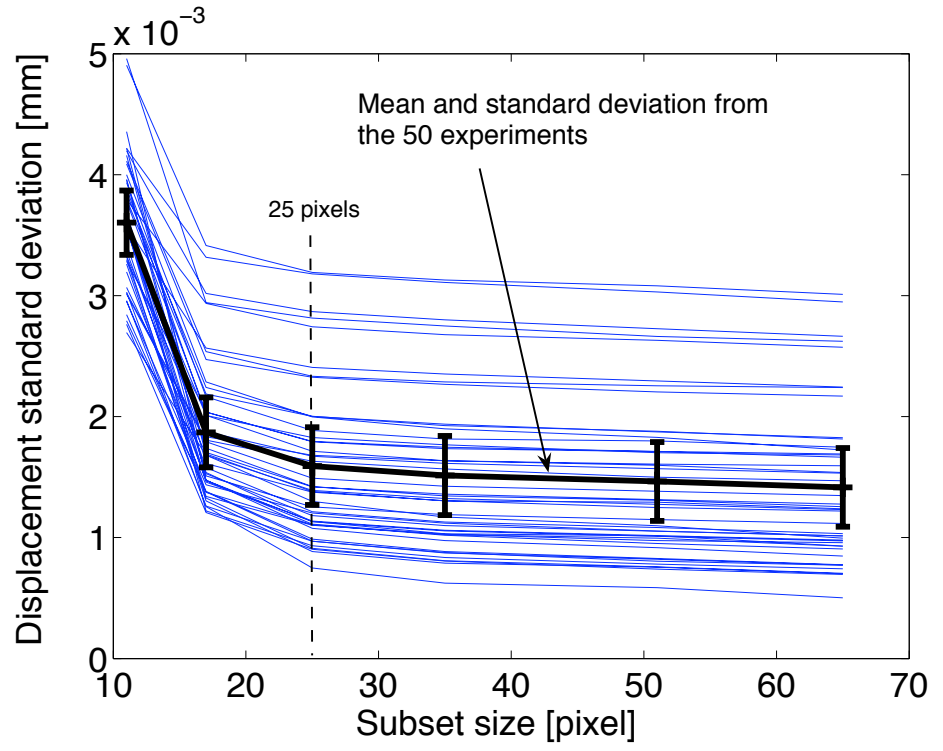

Figure 6: $\sigma(U)$ versus the subset size for 50 imposed solid body displacements of the bending test castable specimen. In large line, the mean value and the standard deviation (error bars) of $\sigma(U)$ for all the experiments are plotted. 


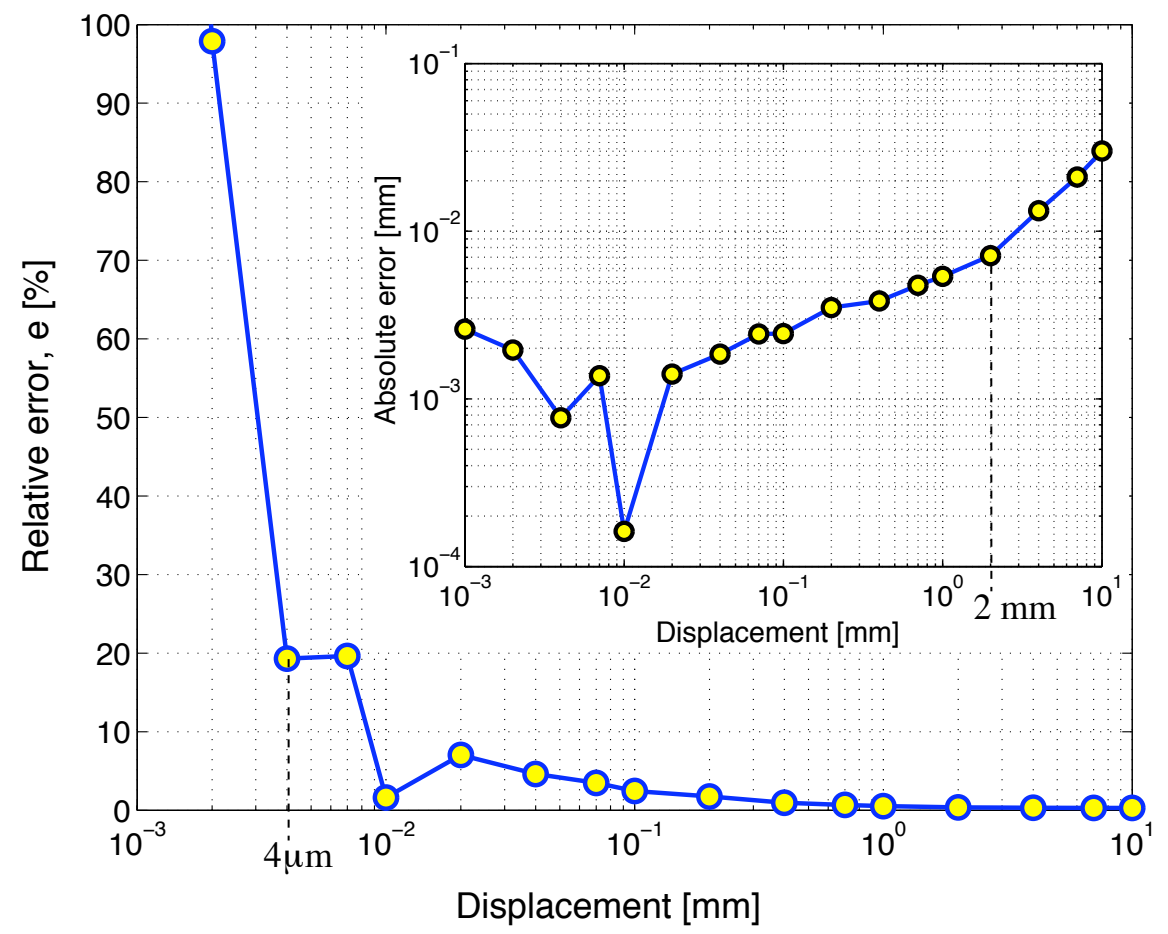

Figure 7: Errors of 3-D DIC measurements on displacements imposed by a $1 \mu \mathrm{m}$ resolution micrometer translation stage. 


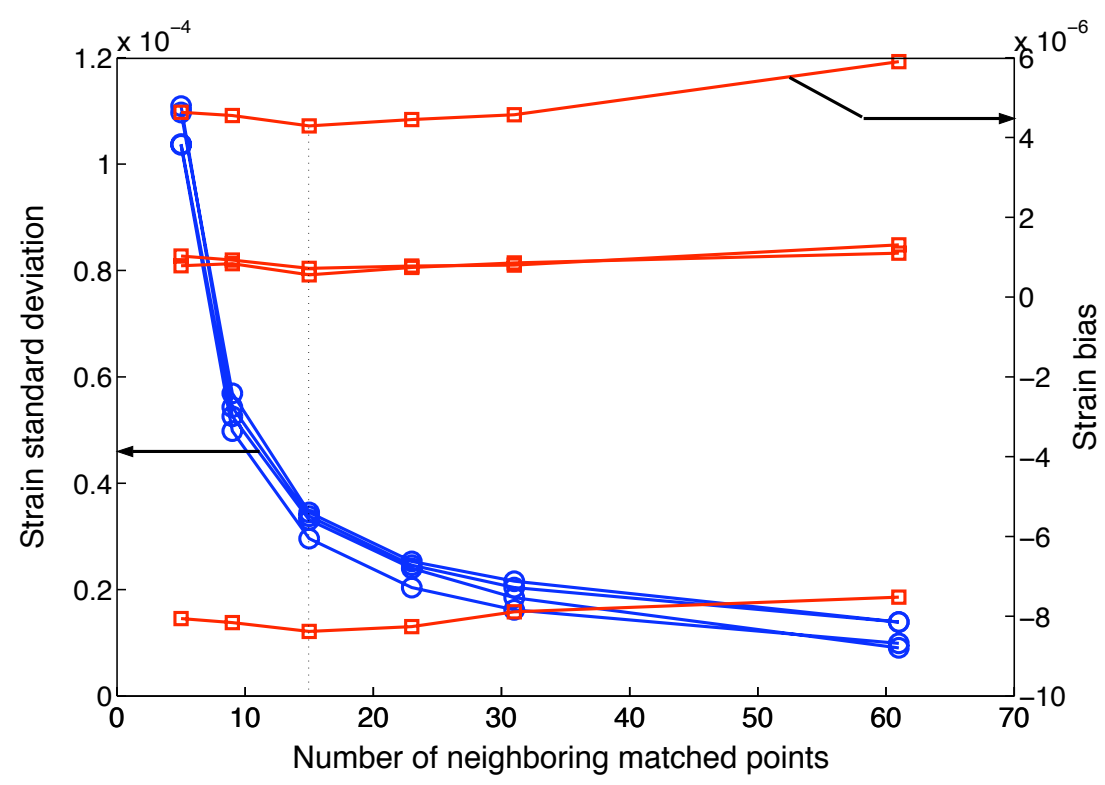

Figure 8: Plots of $\mu(\varepsilon)$ (square) and $\sigma(\varepsilon)$ (circle) calculated by 3-D DIC for specimen images without any movement, versus the nmp parameter. 


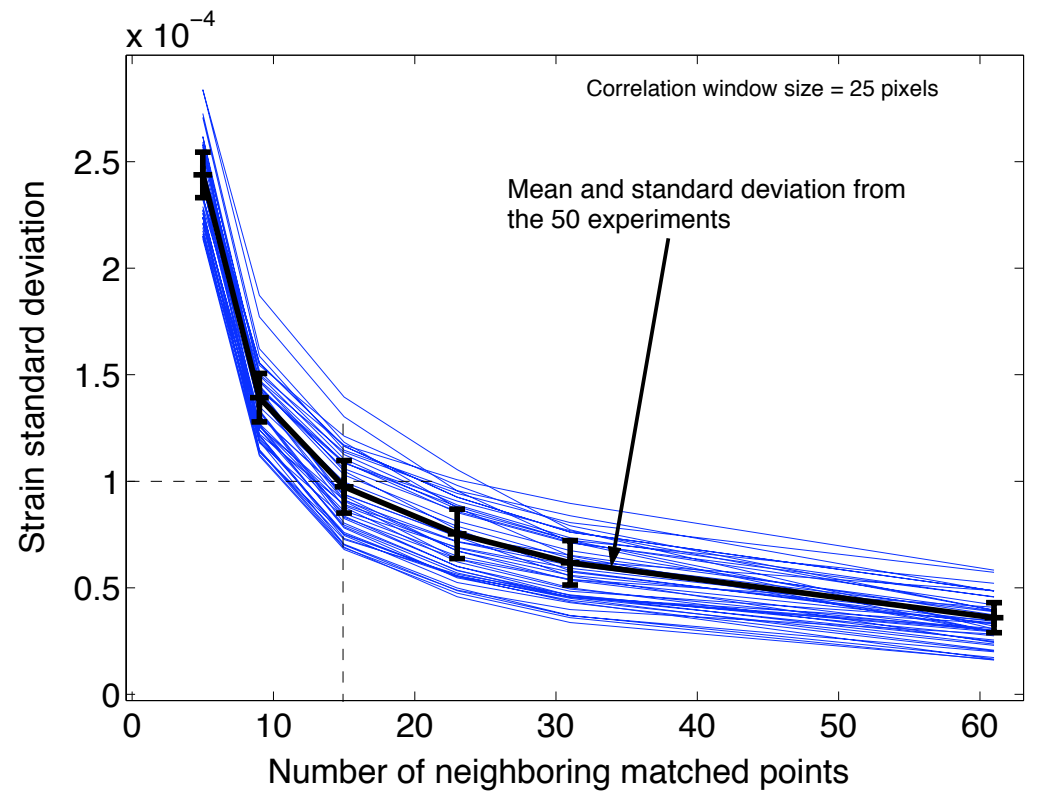

Figure 9: $\sigma(\varepsilon)$ versus the nmp parameter (or optical gauge length) for 50 experiments. As a large line the mean value and the standard deviation (error bars) of $\sigma(\varepsilon)$ for all the experiments are plotted. 


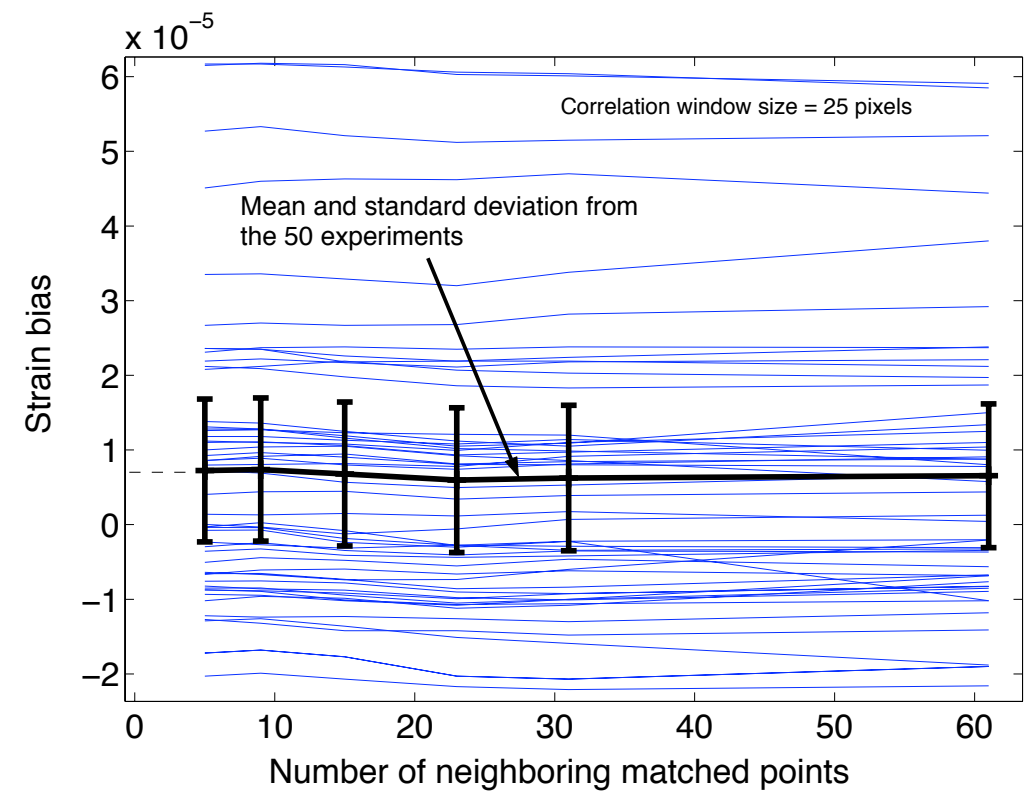

Figure 10: Strain bias versus the nmp parameter (or optical gauge length) for 50 experiments. As a large line the mean value and the standard deviation (error bars) for all the experiments are plotted. 

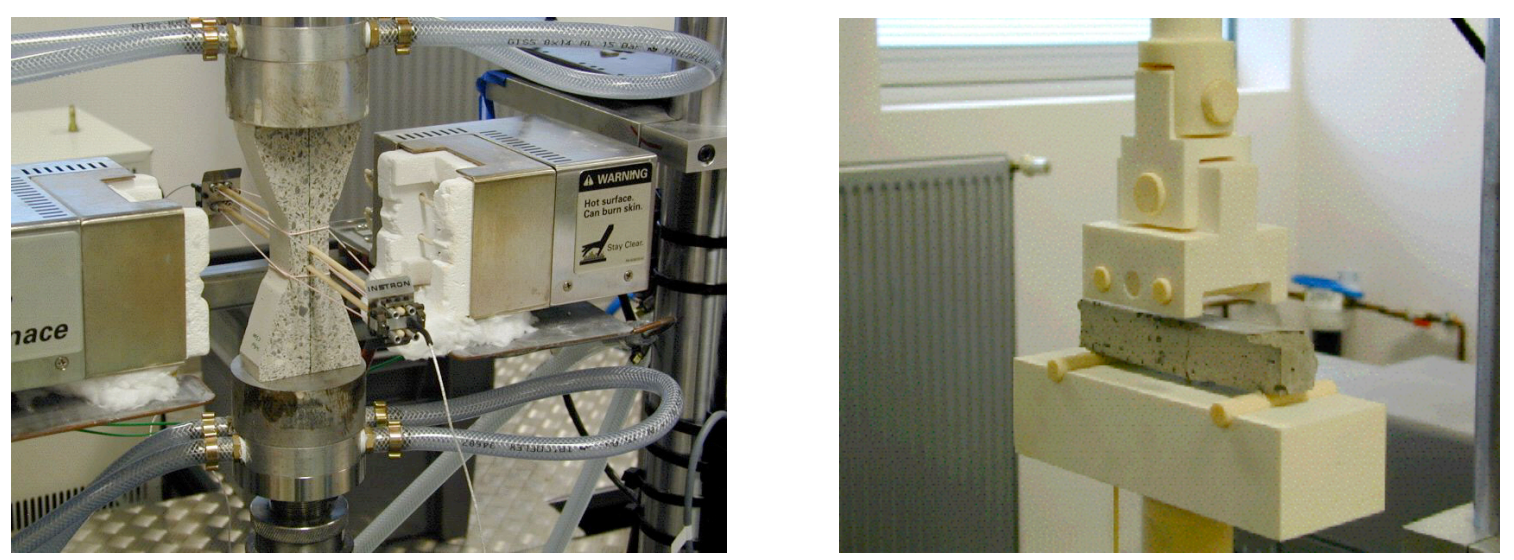

Figure 11: Zoom on the active parts of the tensile test device (left) and of the 4-point bending test device (right) in the room temperature configuration. 

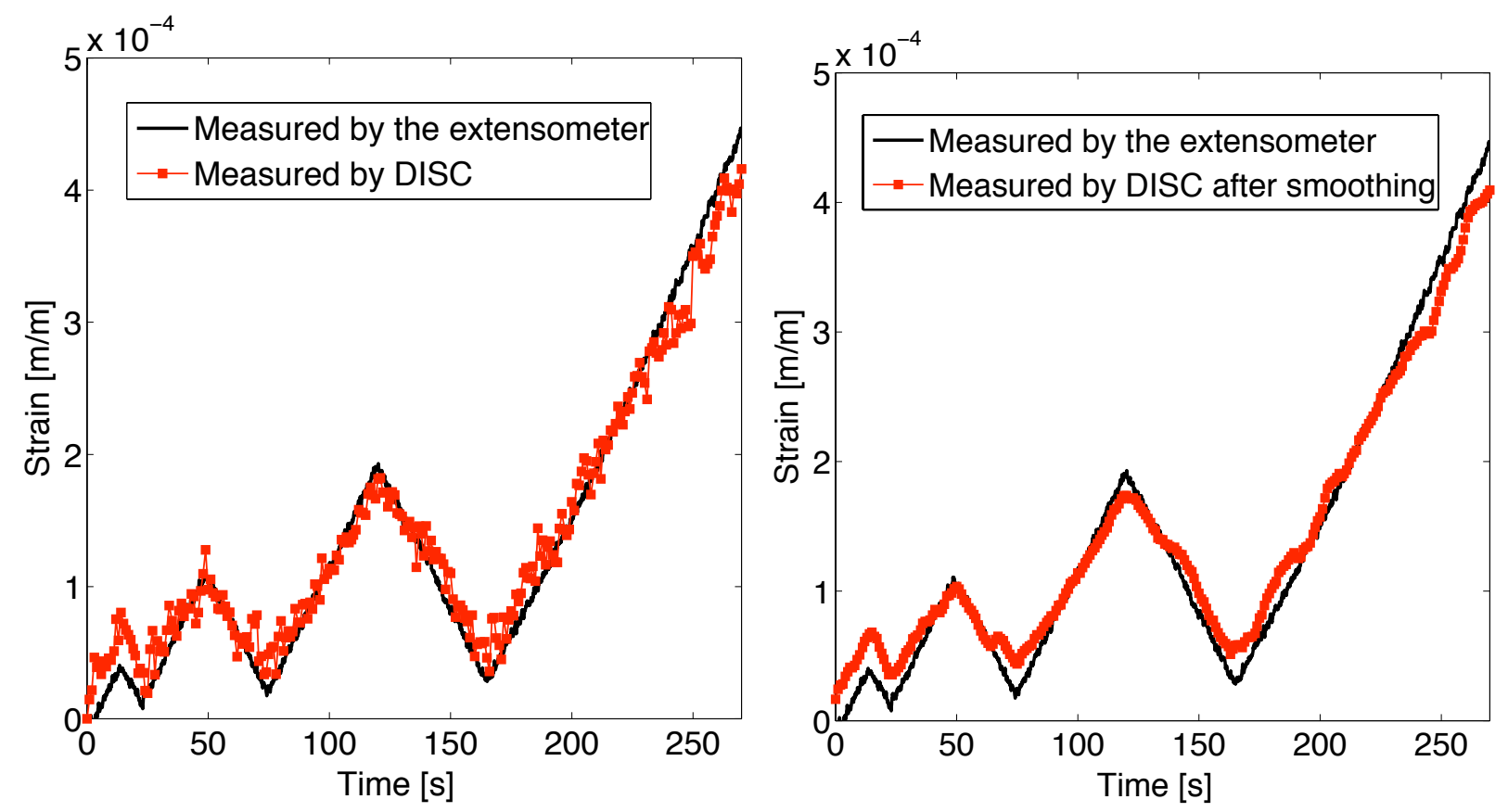

Figure 12: Elastic strain during a cyclic tensile test performed on a FRRC fired at $500^{\circ} \mathrm{C}$. Comparison between strain measured by an extensometer and strain measured by 3-D DIC at each storing time before (left) and after "smoothing" the 3-D DIC values (right). 


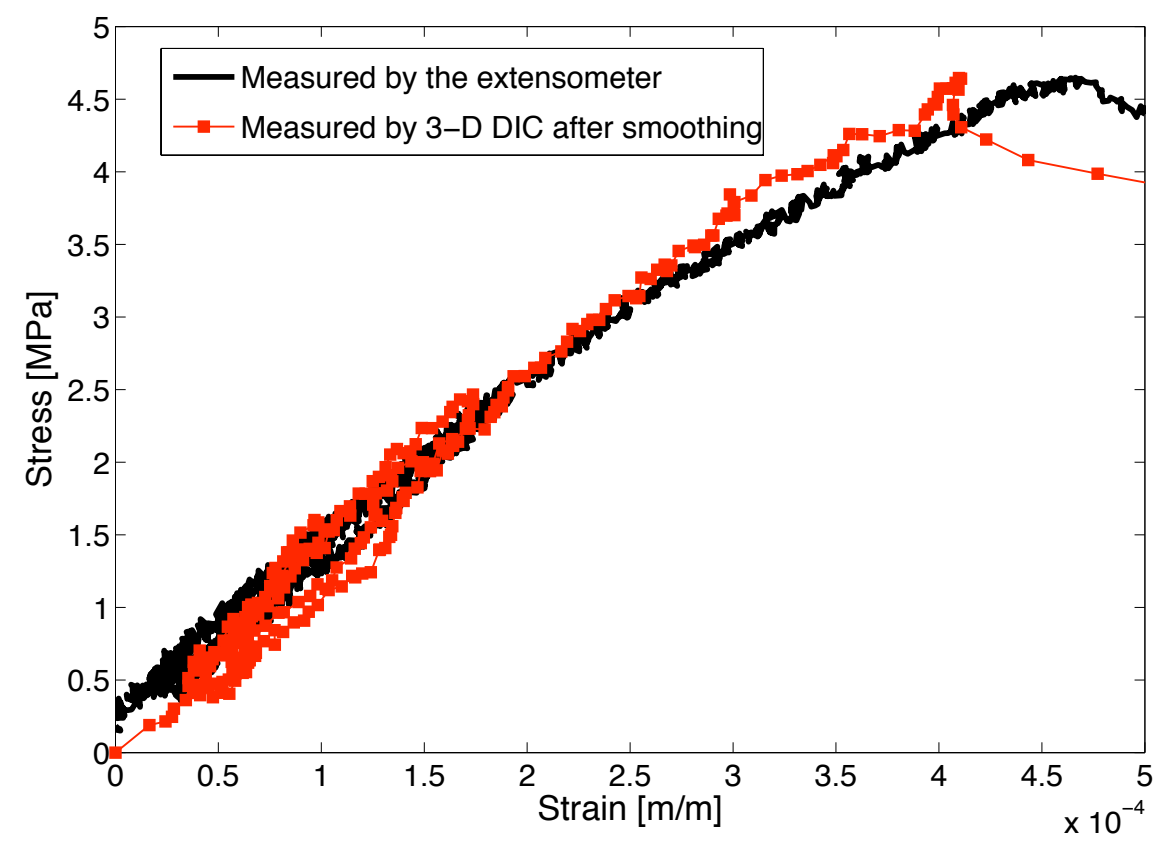

Figure 13: Comparison of behavior curves obtained by 3-D DIC and by an extensometer during a tensile test performed on a FRRC fired at $500^{\circ} \mathrm{C}$. 


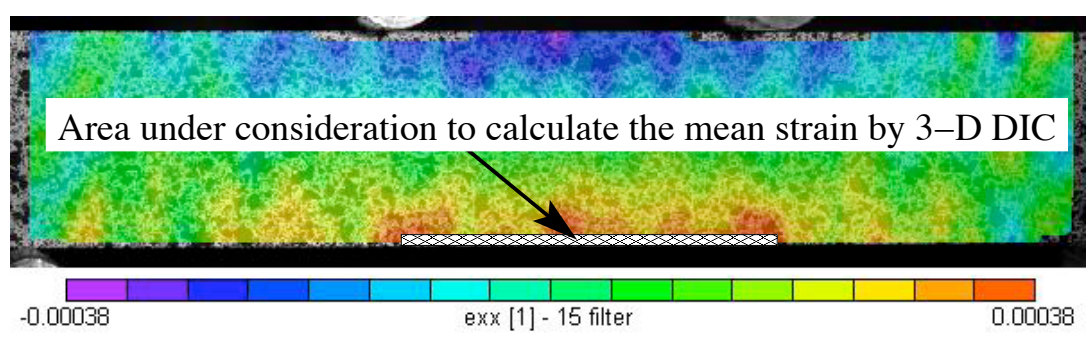

Figure 14: Partial view of a 4-point bending test: description of the area $(45 \mathrm{~mm}$ width by $1 \mathrm{~mm}$ height) which is considered to calculate the mean value of the 3-D DIC longitudinal strain and to determine the FRRC Young's modulus in tension. 


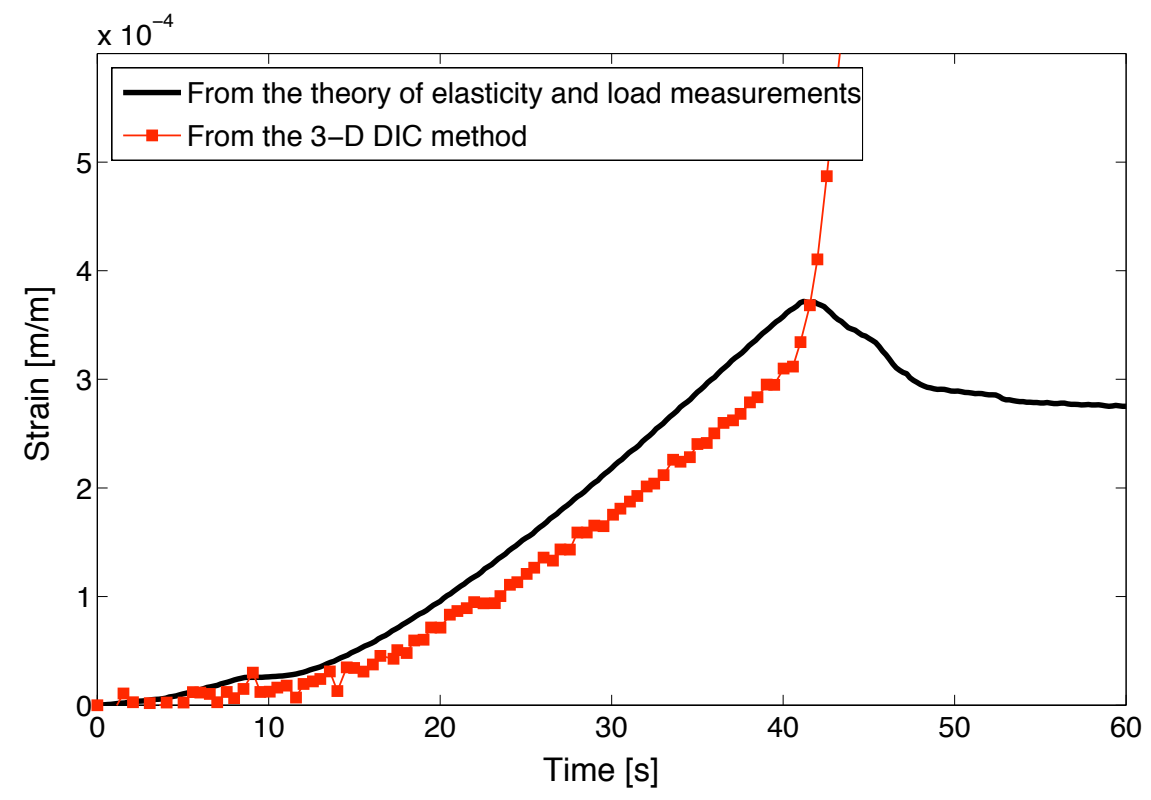

Figure 15: Evolution of the elastic strain during a monotonic 4-point bending test performed on a FRRC sample dried at $110^{\circ} \mathrm{C}$. On one hand strain values are calculated by considering the theory of elasticity (eqn. (6)) and load measurements, on the other hand strain values are obtained from the 3-D DIC method applied on the area defined in Figure 14. 


\begin{tabular}{||l||l|l|l||}
\hline & $\begin{array}{l}\text { Young's modulus } \\
\text { calculated with } \\
\text { extensometers in } \\
\text { the case of tensile } \\
\text { tests [GPa] }\end{array}$ & $\begin{array}{l}\text { Young's modulus } \\
\text { calculated with 3-D } \\
\text { DIC in the case of } \\
\text { tensile tests [GPa] }\end{array}$ & $\begin{array}{l}\text { Young's modulus } \\
\text { calculated with 3-D } \\
\text { DIC in the case } \\
\text { of 4-point bending } \\
\text { tests [GPa] }\end{array}$ \\
\hline \hline FRRC fired at $110^{\circ} \mathrm{C}$ & $30.1 \pm 2.3$ & 31.9 & 33.5 \\
\hline FRRC fired at $500^{\circ} \mathrm{C}$ & $11.5 \pm 1.9$ & 12.9 & 10.1 \\
\hline FRRC fired at $900^{\circ} \mathrm{C}$ & $13.0 \pm 0.8$ & 12.1 & 12.0 \\
\hline
\end{tabular}

Table 1: Comparison between Young's modulus values determined from extensometer measurements and Young's modulus values determined from 3-D DIC in the cases of tensile tests and 4-point bending tests. 